\title{
ANTIPLANE DEFORMATION OF A BIMATERIAL WITH THIN INTERFACIAL NONLINEAR ELASTIC INCLUSION
}

\author{
Heorhiy SULYM*, Yosyf PISKOZUB ${ }^{* *}$, Julian POLANSKI ${ }^{\star * *}$ \\ *Bialystok University of Technology, Faculty of Mechanical Engineering, ul. Wiejska 45c, 15-351 Bialystok, Poland \\ "Ukrainian Academy of Printing, Pidgolosko Str. 19, 79020 L'viv, Ukraine \\ ${ }^{* *}$ University of Bydgoszcz, ul. Unii Lubelskiej 4c, 85-059 Bydgoszcz, Poland \\ h.sulym@pb.edu.pl, piskozub@uad.lviv.uaa, uczelnia@bsw.edu.pl
}

received 13 March 2017, revised 7 August 2018, accepted 10 August 2018

\begin{abstract}
The problem of longitudinal shear of bimaterial with thin nonlinear elastic inclusion at the interface of matrix materials is considered. Solution of the problem is constructed using the boundary value problem of combining analytical functions and jump functions method. The model of the thin inclusion with nonlinear resilient parameters is built. Solution of the problem is reduced to a system of singular integral equations with variable coefficients. The convergent iterative method for solving such a system is offered for various nonlinear strain models, including Ramberg-Osgood law. Numerical calculations are carried out for different values of non-linearity characteristic parameters for the inclusion material. Their parameters are analysed for the tensely-deformed matrix under loading a uniformly distributed shear stresses and for a balanced system of the concentrated forces.
\end{abstract}

Keywords: Antiplane Deformation, Longitudinal Shear, Nonlinear Elasticity, Interfacial Crack, Thin Inclusion, Stress Intensity Factor, Bimaterial, Jump Function, Singular Integral Equation

\section{INTRODUCTION}

Most materials contain numerous subtle defects in the form of cracks and inclusions of various origin (Savruk, 1981; Sulym, 2007; Arhipenko and Kriviy, 2008; Hills et al., 1993). Quite often inclusions are used as structural elements for the reinforcement of machine parts and structures, including as filler composites. One of the characteristic examples of composition material are stratified structures, peculiar to soils (Sekine, 1982; Kit et al., 2003; Ostryk and Ulitko, 2006). Such subtle structural heterogeneity has a complex structure considering possible viscosity, plasticity and other nonlinear effects. The account of non-linearity substantially complicates the process of solving problems and requires the use of various approximate methods even for the bodies of simple geometry (Chernych,1998; Pasternak et al., 2012).

Attempts to take into account non-linearity in an antiplane deformation problem for two compressed half-spaces with interfacial defects were made by different authors including examined sliding friction of contacting bodies (Johnson, 1985; Schmueser et al., 1980; Sulym et al., 2015), boundary element approach (Pasternak et al., 2012).

The aim of this article is a development of jump functions method and construction of adequate models of thin inclusions and layers, material of which has substantially non-linear elastic properties under various loading of body, including multistep or cyclic.

\section{PROBLEM STATEMENT}

Problem statement partly coincides with those considered earlier in Piskozub and Sulym (2008), Sulym (2007) and Sulym et al. 2015).
Consider the isotropic solid consisting of two half-spaces with elastic constants $G_{1}, G_{2}$ and inclusion of small width $2 h$ ( $h \ll$ $a)$, symmetric with respect to the middle line and situated along $L^{\prime}=[-a ; a]$ (Fig. 1) on the interface L of half-spaces. Here the system of co-ordinates $O x y z$ is used, with its origin at the plane $x O z$ of contact of half-spaces, $x O y$ is a cross-section of the solid perpendicular to a direction $\mathrm{z}$ of its longitudinal (out-of-plane) displacement. The half-spaces perpendicular to this axis form half-planes $S_{k}(k=1,2)$, and their interface correspond to the abscissa $\mathrm{L} \sim \mathrm{X}$.

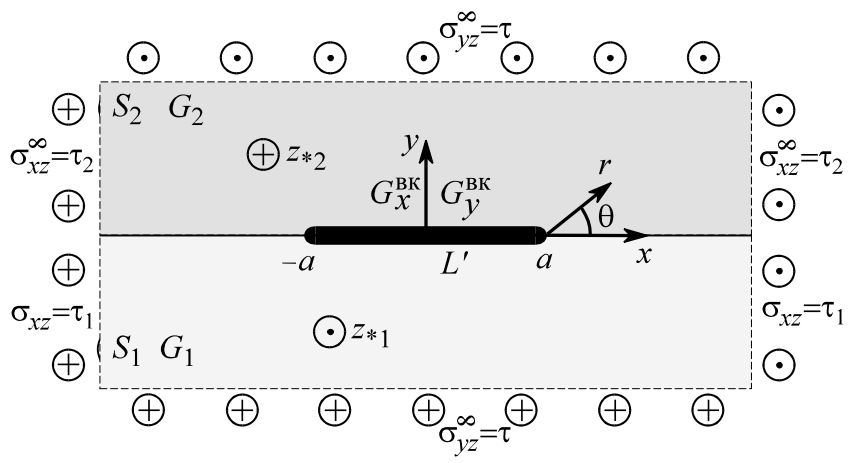

Fig. 1. The loading and geometric scheme of the problem

Suppose that resilient properties of inclusion material are orthotropic nonlinear and satisfy dependences:

$$
\begin{aligned}
& \frac{\partial w^{i n}}{\partial x}=A_{x} \sigma_{x z}^{i n}\left(1+B_{x}\left(\sigma_{x z}^{i n}\right)^{M_{x}}\right), \\
& \frac{\partial w^{i n}}{\partial y}=A_{y} \sigma_{y z}^{i n}\left(1+B_{y}\left(\sigma_{y z}^{i n}\right)^{M_{y}}\right) .
\end{aligned}
$$


Correlations (1) in general case may be presented in a form:

$\sigma_{x z}^{\text {in }}=G_{x}^{\text {in }}\left(\sigma_{x z}^{\text {in }}\right) \frac{\partial w^{\text {in }}}{\partial x}, \quad \sigma_{y z}^{\text {in }}=G_{y}^{\text {in }}\left(\sigma_{y z}^{\text {in }}\right) \frac{\partial w^{\text {in }}}{\partial y}$

with the variable shear modules $G_{x}^{\text {in }}\left(\sigma_{x z}^{\text {in }}\right), G_{y}^{\text {in }}\left(\sigma_{y z}^{\text {in }}\right)$. In the case of $\mathrm{M}_{\mathrm{s}}=\mathrm{m}_{\mathrm{s}}-1, \mathrm{~A}_{\mathrm{s}}=1 / \mathrm{G}_{\mathrm{os}}, \mathrm{B}_{\mathrm{s}}=\mathrm{K}_{\mathrm{s}} \mathrm{A}_{\mathrm{s}}^{\mathrm{m}_{\mathrm{s}}-1}, \mathrm{~s}=\{\mathrm{x} ; \mathrm{y}\}$ correlation (1) coincides with the Ramberg-Osgood (Chernych, 1998; Rice and Rosengren, 1968) strain model, where $G_{o s}, m_{s}$, $\mathrm{K}_{\mathrm{s}}, \mathrm{s}=\{\mathrm{x} ; \mathrm{y}\}$ are the nonlinear elastic parameters of the inclusion material.

Intensity and direction of action of the external power factors (stress at the infinity, concentrated forces, etc.) causes the quasistatic stress strain state (SSS) in the bimaterial solid with inclusion. Let the external loading of the problem be defined by the following factors: stresses $\sigma_{\mathrm{yz}}^{\infty}=\tau, \sigma_{\mathrm{xzk}}^{\infty}=\tau_{\mathrm{k}}$ uniformly distributed at the infinity; concentrated forces with magnitude $Q_{k}$, and screw dislocations with Burgers vectors $b_{k}$ applied at the points $\mathrm{Z}_{\mathrm{k}} \in \mathrm{S}_{\mathrm{k}}(\mathrm{k}=1,2)$. Concordantly (Sulym, 2007) tensions $\sigma_{\mathrm{xzk}}^{\infty}=\tau_{\mathrm{k}}$ must satisfy the condition $\tau_{2} \mathrm{G}_{1}=\tau_{1} \mathrm{G}_{2}$ which provides the straightforwardness of the interface line on the infinity.

The application of similar traditional notation for an axis $\mathrm{z}$ and a complex variable $\mathrm{z}=\mathrm{x}+$ iy should not cause misunderstanding in the solution of the problem.

As well as in works (Bozhydarnyk and Sulym, 1999; Sulym, 2007; Piskozub and Sulim, 2008; Sulym and Piskozub, 2004; Pasternak et al., 2010) the presence of thin defect (inclusion) is modelled by stress and displacement discontinuity vectors at $\mathrm{L}^{\prime}$ :

$[\Phi] \equiv \Phi^{-}-\Phi^{+}=\mathbf{f}(x)$,

where $\Phi(\mathrm{z})=\left\{\sigma_{\mathrm{yz}}, \partial \mathrm{w} / \partial \mathrm{x}\right\}(\mathrm{z})$ is vector of state; $\mathrm{f}(\mathrm{x})=$ $\left\{\mathrm{f}_{3}, \mathrm{f}_{6}\right\}(\mathrm{x})$ is jump vector. Notations $[\phi]_{\mathrm{h}}=\phi(\mathrm{x},-\mathrm{h})-$ $\phi(\mathrm{x}, \mathrm{h}),\langle\phi\rangle_{\mathrm{h}}=\phi(\mathrm{x},-\mathrm{h})+\phi(\mathrm{x}, \mathrm{h})$ are used hereinafter; indexes "+" and "-" match the boundary values of functions on the overhead and bottom edges of line L.

Taking into account the Hooke's law expression (3) gives:

$\left[\sigma_{y z}\right]_{h} \cong \sigma_{y z}^{-}-\sigma_{y z}^{+}=f_{3}(x)$,

$\left[\frac{\partial w}{\partial x}\right]_{h} \cong \frac{\partial w^{-}}{\partial x}-\frac{\partial w^{+}}{\partial x}=\left[\frac{\sigma_{x z}}{G}\right]_{h} \equiv$

$\equiv \frac{\sigma_{x z}^{-}}{G_{1}}-\frac{\sigma_{x z}^{+}}{G_{2}}=f_{6}(x), x \in L^{\prime}$;

$f_{3}(x)=f_{6}(x)=0 \quad$, if $x \notin L^{\prime}$.

The model of thin inclusion is given in terms of interaction (Sulym, 2007; Piskozub and Sulim, 2008), which from the point of view of mathematical design are equivalent to the terms of imperfect contact between the opposite matrix surfaces adjacent to the inclusion. Proposed the thin object modelling techniques is based on the principle of integrating the defining relationships describing the physical and mechanical properties of the inclusion material with the following taking into account the smallness one of the linear dimensions of inclusion:

$\left\{\begin{array}{l}G_{x}^{i n}\left(\sigma_{x z}^{i n}\right)\left\langle\frac{\partial w^{i n}}{\partial x}\right\rangle_{h}(x)-2 \sigma_{x z}^{i n}(-a)-\frac{1}{h} \int_{-a}^{x}\left[\sigma_{y z}^{i n}\right]_{h}(\xi) d \xi=0, \\ G_{y}^{i n}\left(\sigma_{y z}^{i n}\right)\left[w^{i n}\right]_{h}(x)+h\left\langle\sigma_{y z}^{i n}\right\rangle_{h}(x)=0 .\end{array}\right.$
Contact between the bimaterial medium components along a line $\mathrm{L}^{\prime \prime}=\mathrm{L} \backslash \mathrm{L}^{\prime}$ and between medium components and inclusion at $\mathrm{L}^{\prime}$ is supposed to be mechanically perfect:

$w^{\text {in }}(x, \pm h)=w_{k}(x, \pm h), \quad x \in L^{\prime}$

$\sigma_{y z}^{i n}(x, \pm h)=\sigma_{y z k}(x, \pm h)$.

\section{THE PROBLEM SOLUTION}

Using the known approach (Sulym, 2007; Piskozub and Sulym, 2008; Sulym et al., 2015) it is possible to get dependences according to which SSS components are defined by relations:

$$
\begin{aligned}
& \sigma_{y z}^{ \pm}(x)=\mp p_{k} f_{3}(x)-C g_{6}(x)+\sigma_{y z}^{0 \pm}(x), \\
& \sigma_{x z}^{ \pm}(x)=\mp C f_{6}(x)+p_{k} g_{3}(x)+\sigma_{x z}^{0 \pm}(x), \\
& g_{r}(z) \equiv \frac{1}{\pi} \int_{L^{\prime}} \frac{f_{r}(x) d x}{x-z} \\
& p_{k}=\frac{G_{k}}{G_{1}+G_{2}}, C=G_{3-k} p_{k}, \\
& \sigma_{y z}(z)+i \sigma_{x z}(z)=\sigma_{y z}^{0}(z)+i \sigma_{x z}^{0}(z)+ \\
& +i p_{k} g_{3}(z)-C g_{6}(z) \\
& \left(z \in S_{k} ; r=3,6 ; k=1,2\right) .
\end{aligned}
$$

Terms, marked an index "0" from above, characterize corresponding terms in a solid without model heterogeneities (inclusions, cracks, etc.) under the corresponding external loading (homogeneous solution).

Hereinafter:

$\sigma_{y z}^{0}(z)+i \sigma_{x z}^{0}(z)=\tau+i\left\{\tau_{k}+D_{k}(z)+\right.$

$\left.+\left(p_{k}-p_{j}\right) \bar{D}_{k}(z)+2 p_{k} D_{j}(z)\right\}$,

$D_{k}(z)=-\frac{Q_{k}+i G_{k} b_{k}}{2 \pi\left(z-z_{* k}\right)}$

$\left(z \in S_{k}, k=1,2 ; j=3-k\right)$,

Using (7), (8) and boundary conditions (6) it is easy to get from the model (5) a system of singular integral equations (SSIE):

$$
\begin{aligned}
& \left\{\begin{array}{l}
\left(p_{2}-p_{1}\right) f_{6}(x)+2 p g_{3}(x)-\frac{1}{h G_{x}^{i n}} \int_{-a}^{x} f_{3}(\xi) d \xi=F_{3}(x), \\
\left(p_{2}-p_{1}\right) f_{3}(x)+2 C g_{6}(x)-\frac{G_{y}^{i n}}{h} \int_{-a}^{x} f_{6}(\xi) d \xi=F_{6}(x),
\end{array}\right. \\
& F_{3}(x)=\frac{2}{G_{x}^{i n}} \sigma_{x z}^{i n}(-a)-\left(\sigma_{x z 2}^{0}(x) / G_{2}+\sigma_{x z 1}^{0}(x) / G_{1}\right), \\
& F_{6}(x)=\left\langle\sigma_{y z}^{0}\right\rangle(x)-G_{y}^{i n}\left\langle\frac{\sigma_{y z k}^{0}(x)}{G_{k}}\right\rangle-\frac{G_{y}^{i n}}{h}\left[\begin{array}{c}
0 \\
w
\end{array}\right](-a),
\end{aligned}
$$

with the additional conditions on power balance and unambiguity of displacements while going round the thin defect:

$\int_{-a}^{a} f_{3}(\xi) d \xi=2 h\left(\sigma_{x z}^{i n}(a)-\sigma_{x z}^{i n}(-a)\right)$,

$\int_{-a}^{a} f_{6}(\xi) d \xi=[w](a)-[w](-a)$.

Here:

$\left\langle\sigma_{y z}^{0}+i \sigma_{x z}^{0}\right\rangle(x)=2 \tau+i\left(\tau_{1}+\tau_{2}\right)+$
$+i\left\{\left(3 p_{1}+p_{2}\right) D_{2}(x)+\left(p_{2}-p_{1}\right) \bar{D}_{2}(x)+\right.$
$\left.+\left(3 p_{2}+p_{1}\right) D_{1}(x)+\left(p_{1}-p_{2}\right) \bar{D}_{1}(x)\right\}$ 
For partial cases SSIE (9) is simplify, in particular:

- A) materials of the matrix are the same: $G_{1}=G_{2}=G$ :

$\left\{\begin{array}{l}\frac{1}{G} g_{3}(x)-\frac{1}{h G_{x}^{i n}\left(\sigma_{x z}^{i n}\right)} \int_{-a}^{x} f_{3}(\xi) d \xi=F_{3}(x), \\ G g_{6}(x)-\frac{G_{y}^{i n}\left(\sigma_{y z}^{i n}\right)}{h} \int_{-a}^{x} f_{6}(\xi) d \xi=F_{6}(x),\end{array}\right.$

- B) crack: $G_{x}^{i n}\left(\sigma_{x z}^{i n}\right), \quad G_{y}^{i n}\left(\sigma_{y z}^{i n}\right) \rightarrow 0$ :

$\left\{\begin{array}{l}g_{6}(x)=\frac{\left\langle\sigma_{y z}^{0}\right\rangle_{h}(x)}{2 C}, \\ f_{3}(x)=0\end{array}\right.$

- C) absolutely hard inclusion:

$\left\{\begin{array}{l}\int_{-a}^{x} f_{6}(\xi) d \xi=-\left[\begin{array}{c}0 \\ w\end{array}\right](-a)=0 \rightarrow f_{6}(x)=0, \\ g_{3}(x)=-\frac{1}{2 h}\left(\sigma_{x z 2}^{0}(x) / G_{2}+\sigma_{x z 1}^{0}(x) / G_{1}\right) .\end{array}\right.$

Cases B), C) have a close analytical solution which coincides with the known results (Comninou, 1977; Panasyuk et al., 1976; Schmueser et al., 1980; Savruk, 1981).

A study of the characteristic part of SSIE (9), (12) proves that it does not depend on nonlinear terms. Solving of SSIE (9), (12) is more comfortable when we transform it to a dimensionless kind:

$\left\{\begin{array}{l}\alpha \tilde{f}_{6}(\tilde{x})+\beta \tilde{g}_{3}(\tilde{x})-\eta_{3} \int_{-1}^{\tilde{x}} \tilde{f}_{3}(\xi) d \xi=\tilde{F}_{3}\left(\tilde{x}, \sigma_{x z}^{i n}\right), \\ \alpha \tilde{f}_{3}(\tilde{x})+\beta \tilde{g}_{6}(\tilde{x})-\eta_{6} \int_{-1}^{\tilde{x}} \tilde{f}_{6}(\xi) d \xi=\tilde{F}_{6}\left(\tilde{x}, \sigma_{y z}^{i n}\right),\end{array}\right.$

where:

$\alpha=\left(p_{2}-p_{1}\right), \quad \beta=2 \tilde{C}, \quad \eta_{3}=1 / \tilde{h} \tilde{G}_{x}^{i n}\left(\sigma_{x z}^{i n}\right)$,

$\eta_{6}=\tilde{G}_{y}^{i n}\left(\sigma_{y z}^{i n}\right) / \tilde{h}, \quad \tilde{x}=x / a, \tilde{h}=h / a, \tilde{y}=y / a$,

$\tilde{G}_{x}^{i n}=G_{x}^{i n} / G_{g a v}, \tilde{G}_{y}^{i n}=G_{y}^{i n} / G_{g a v}$,

$\tilde{f}_{3}=G_{g a v} f_{3}, \quad \tilde{f}_{6}=f_{6}, \quad \tilde{C}=C / G_{\text {gav }}$,

$\tilde{F}_{3}=F_{3} / G_{g a v}, \tilde{F}_{6}=F_{6} / G_{g a v}, \quad G_{g a v}=\sqrt{G_{1} G_{2}}$.

Expanding the jump functions $\tilde{f}_{r}(x)$ as series of Chebyshev polynomials:

$\tilde{f}_{r}(x)=\frac{1}{\sqrt{1-\tilde{x}^{2}}} \sum_{j=0}^{n} B_{j}^{r} T_{j}(\tilde{x}), \quad(r=3,6)$

with the use of (16) and the known integrals we obtain:

$\tilde{g}_{r}(\tilde{x})=\sum_{j=1}^{n} B_{j}^{r} U_{j-1}(\tilde{x})$,

$\int_{-1}^{\tilde{x}} \tilde{f}_{r}(\xi) d \xi=\left(\frac{\pi}{2}+\arcsin \tilde{x}\right) B_{0}^{r}-$

$-\sqrt{1-\tilde{x}^{2}} \sum_{j=1}^{n} B_{j}^{r} \frac{U_{j-1}(\tilde{x})}{j}$,

$\int_{-1}^{1} \tilde{f}_{r}(\xi) d \xi=B_{0}^{r}$

Substitution (16)-(19) in (15), (20) at the set of points $x_{m}=$ $\cos \frac{m \pi}{n+1} \quad(m=\overline{1, n})$ gives the system of algebraic equations $(\mathrm{SAE})$ of order $2 \mathrm{n}+2$ on unknown $\mathrm{B}_{\mathrm{j}}^{\mathrm{r}}$ :

$\left\{\begin{array}{l}\sum_{j=0}^{n} \chi_{m j}^{3} B_{j}^{3}+\sum_{j=0}^{n} \omega_{m j} B_{j}^{6}=\tilde{F}_{3}\left(x_{m}, \tilde{G}_{x m}^{i n}\right), \\ \sum_{j=0}^{n} \omega_{m j} B_{j}^{3}+\sum_{j=0}^{n} \chi_{m j}^{6} B_{j}^{6}=\widetilde{F}_{6}\left(x_{m}, \tilde{G}_{y m}^{i n}\right), \\ B_{0}^{3}=2 \tilde{h}\left(\sigma_{x z}^{i n}(a)-\sigma_{x z}^{i n}(-a)\right) / G_{g a v}, \\ B_{0}^{6}=[\widetilde{w}](a)-[\widetilde{w}](-a), \quad m=\overline{1, n}\end{array}\right.$

where are used denotations:

$$
\begin{aligned}
& \chi_{j m}^{3}=-\delta_{0 j} \frac{\gamma_{m}}{\tilde{G}_{x m}^{i n}}+\left(1-\delta_{0 j}\right)\left(\frac{\mu_{j m}}{\tilde{G}_{x m}^{i n}}+2 \tilde{C}\right) \rho_{j m}, \\
& \chi_{j m}^{6}=-\delta_{0 j} \tilde{G}_{y m}^{i n} \gamma_{m}+\left(1-\delta_{0 j}\right)\left(\tilde{G}_{y m}^{i n} \mu_{j m}+2 \tilde{C}\right) \rho_{j m}, \\
& \omega_{j m}=\frac{\left(p_{2}-p_{1}\right) T_{j}\left(x_{m}\right)}{\sqrt{1-x_{m}^{2}}}, \mu_{j m}=\frac{\sqrt{1-x_{m}^{2}}}{j \widetilde{h}}, \\
& \gamma_{m}=\frac{\pi}{\widetilde{h}}\left(1-\frac{m}{n+1}\right), \quad \rho_{j m}=U_{j-1}\left(x_{m}\right), \\
& \tilde{G}_{r m}^{i n}=\tilde{G}_{r}^{i n}\left(x_{m}\right), \quad r=\{3,6\}, \\
& \delta_{0 j}-\text { Kronecker symbol. }
\end{aligned}
$$

Dependence $G_{x}^{i n}\left(\sigma_{x z}^{i n}\right), G_{y}^{i n}\left(\sigma_{y z}^{i n}\right)$ on current SSS generates serious complications in solving the problem because of its changeableness along $\mathrm{L}$. The following strategy of calculation is proposed:

- At the initial step values $G_{0 x}^{\text {in }}, G_{0 y}^{\text {in }}$ are used as $G_{x}^{\text {in }}\left(\sigma_{x z}^{\text {in }}\right)$, $\mathrm{G}_{\mathrm{y}}^{\mathrm{in}}\left(\sigma_{\mathrm{yz}}^{\mathrm{in}}\right)$. These values are the same in all collocation points $\mathrm{x}_{\mathrm{m}} \quad(\mathrm{m}=\overline{1, \mathrm{n}})$. SAE is linear.

- The external loading begins with some chosen variant of loading scheme (values $\tau, \tau_{k}, Q_{k}, z_{* k}, b_{k}$ ). Solve the SAE. Use obtained $B_{j}^{r}(r=3,6 ; j=\overline{0, n})$ in correlations (16) -(19) to get from (7) components of SSS in each of collocation points.

- Calculate the new current value of $G_{x}^{\text {in }}\left(\sigma_{x z}^{\text {in }}\right), G_{y}^{\text {in }}\left(\sigma_{y z}^{\text {in }}\right)$ from (2). Checks whether the relation (1) executes at every collocation point. If so, then pass to the next step of loading, choosing corresponding for every collocation point obtained values $G_{x}^{\text {in }}\left(\sigma_{x z}^{\text {in }}\right), G_{y}^{\text {in }}\left(\sigma_{y z}^{\text {in }}\right)$. If no, then minimize deviation of the calculated shear modulus in relation (2), repeating a calculation with new, obtained for this SSS in (1) by the values of the current shear modulus in every collocation point. Recalculation repeats until sufficient exactness is achieved. The iteration process is convergent (tested). Calculation for the next step loading begins with using of values $G_{x}^{\text {in }}\left(\sigma_{x z}^{\text {in }}\right)$, $\mathrm{G}_{\mathrm{y}}^{\mathrm{in}}\left(\sigma_{\mathrm{yz}}^{\mathrm{in}}\right)$ obtained on the previous step.

Introduction of a system of polar co-ordinates $(r, \theta)$ with the origin near the right or the left tip of the inclusion $z= \pm r$. $\exp (i \theta) \pm \mathrm{a}$ (Fig. 1), makes it possible to obtain two-term asymptotic expressions for the distribution of the stresses and displacements in the vicinity of the tips $\left(\left|z_{1}\right|<<2 a\right)$ (Sulym, Piskozub, 1996; Sulym, 2007). Consider the generalized stress intensity factors (GSIF) introduced by expression:

$$
K_{31}+i K_{32}=\lim _{r \rightarrow 0} \sqrt{(\theta=0, \pi)} \sqrt{2 \pi r}\left(\sigma_{y z}+i \sigma_{x z}\right) .
$$

Using (7), (16) -(19) it is simple to obtain the formulae:

$$
K_{31}^{ \pm}+i K_{32}^{ \pm}=2 \sqrt{\pi a G_{g a v}} \sum_{j=0}^{n}( \pm 1)^{j}\left(\tilde{C} B_{j}^{6}-i p_{k} B_{j}^{3}\right) .
$$

\section{THE NUMERICAL ANALYSIS}

For definiteness we accept the strain model as RambergOsgood:

$$
\begin{gathered}
\frac{\partial w^{i n}}{\partial x}=\frac{\sigma_{x z}^{i n}}{G_{0 x}}\left(1+K_{x}\left(\frac{\sigma_{x z}^{i n}}{G_{0 x}}\right)^{m_{x}-1}\right), \\
\frac{\partial w^{i n}}{\partial y}=\frac{\sigma_{y z}^{i n}}{G_{0 y}}\left(1+K_{y}\left(\frac{\sigma_{y z}^{i n}}{G_{0 y}}\right)^{m_{y}-1}\right) .
\end{gathered}
$$


Then from (2) one can get:

$$
\begin{aligned}
G_{x}^{i n}\left(\sigma_{x z}^{i n}\right) & =\frac{G_{0 x}}{1+K_{x}\left(\sigma_{x z}^{i n} / G_{0 x}\right)^{m_{x}-1}}, \\
G_{y}^{i n}\left(\sigma_{y z}^{i n}\right) & =\frac{G_{0 y}}{1+K_{y}\left(\sigma_{y z}^{i n} / G_{0 y}\right)^{m_{y-1}}}
\end{aligned}
$$

or in the dimensionless kind:

$\tilde{G}_{x}^{i n}\left(\sigma_{x z}^{i n}\right)=\frac{\tilde{G}_{0 x}}{1+K_{x}\left(\widetilde{\sigma}_{x z}^{i n} / \tilde{G}_{0 x}\right)^{m_{x-1}}}$,

$\tilde{G}_{0 x}=G_{0 x} / G_{g a v}, \quad \tilde{G}_{x}^{i n}\left(\sigma_{x z}^{i n}\right)=G_{x}^{i n}\left(\sigma_{x z}^{i n}\right) / G_{g a v}$

$\tilde{G}_{y}^{i n}\left(\sigma_{y z}^{i n}\right)=\frac{\tilde{G}_{0 y}}{1+K_{y}\left(\widetilde{\sigma}_{y z}^{i n} / \tilde{G}_{0 y}\right)^{m_{y^{-1}}}}$,

$\tilde{G}_{0 y}=G_{0 y} / G_{g a v}, \quad \tilde{G}_{y}^{i n}\left(\sigma_{x z}^{i n}\right)=G_{y}^{i n}\left(\sigma_{y z}^{i n}\right) / G_{g a v}$.

Consider also the following dimensionless values, which significantly reduce the amount of calculations without loss in generality: $G_{d}=G_{2} / G_{1}, \tilde{\tau}_{k}=\tau_{k} / G_{\text {gav }}, \tilde{\tau}=\tau / G_{\text {gav }}$, $\widetilde{\mathrm{Q}}_{\mathrm{k}}=\mathrm{Q}_{\mathrm{k}} / \mathrm{a} \pi \mathrm{G}_{\mathrm{gav}}, \tilde{\mathrm{z}}_{* \mathrm{k}}=\mathrm{z}_{* \mathrm{k}} / \mathrm{a}=\tilde{\mathrm{x}}_{* \mathrm{k}}+\mathrm{i} \tilde{\mathrm{y}}_{* \mathrm{k}}$ are the relation of matrix shear modulus, intensity of loading factors and coordinates of the concentrated force application points, respectively.

Fig. 2-9 illustrates the changing of the dimensionless GSIF values $\widetilde{\mathrm{K}}_{31}=\frac{\mathrm{K}_{31}^{+}}{2 \widetilde{\mathrm{C} G} \mathrm{G}_{\text {gav }} \sqrt{\pi \mathrm{a}}}, \widetilde{\mathrm{K}}_{32}=\frac{\mathrm{K}_{32}^{+}}{2 \mathrm{p}_{2} \mathrm{G}_{\text {gav }} \sqrt{\pi \mathrm{a}}}$ for some schemes of external loading: uniformly distributed at the infinity stress $\tilde{\tau}$ (scheme 1), $\tilde{\tau}_{k}$ (scheme 2), concentrated forces with magnitude $\mathrm{Q}$ applied at the points $\tilde{\mathrm{z}}_{\mathrm{k}}$ (scheme $3: \mathrm{Q}_{2}=-\mathrm{Q}_{1}=\mathrm{Q}, \mathrm{z}_{2}=$ $-\mathrm{z}_{1}=\mathrm{iy}_{2} ;$ scheme $4: \quad \mathrm{Q}_{2}=-\mathrm{Q}_{1}=\mathrm{Q} ; \quad \mathrm{z}_{2}=-\mathrm{z}_{1}=\mathrm{x}_{2} ;$ scheme 5: $\mathrm{Q}_{2}=-\mathrm{Q}_{1}=\mathrm{Q}, \mathrm{z}_{2}=\overline{\mathrm{z}}_{1}=\mathrm{x}_{2}+$ iy) and parameters of nonlinear resiliency.
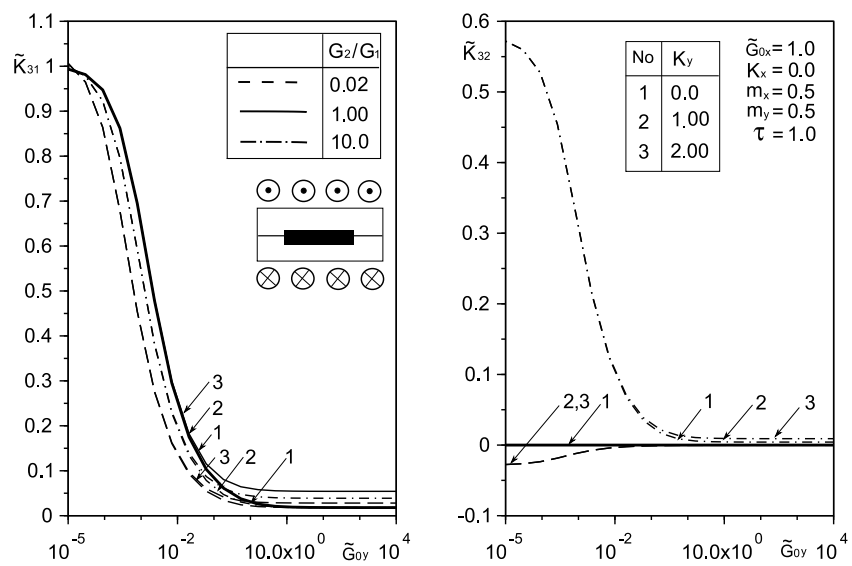

Fig. 2. Dependence of the stress intensity factors $\widetilde{\boldsymbol{K}}_{31}, \widetilde{\boldsymbol{K}}_{32}$ on the nonlinear elastic parameters $\boldsymbol{K}_{\boldsymbol{y}}, \boldsymbol{G}_{\boldsymbol{d}}$ (scheme 1)

As expected, nonzero values $\widetilde{\mathrm{K}}_{32}$ appeared in scheme 1 only while $G_{d} \neq 1$ (Fig. 2,3). The increase of the parameter $K_{y}$ leads to the insignificant increase GSIF, unlike the influence of $G_{d}$. Scheme of loading 2 practically does not cause $\widetilde{\mathrm{K}}_{31}$. Influence $\mathrm{K}_{\mathrm{s}}, \mathrm{m}_{\mathrm{s}}, \mathrm{s}=\{\mathrm{x} ; \mathrm{y}\}$ on $\widetilde{\mathrm{K}}_{32}$ is unnoticeable in this scheme.

As shown by the numerical experiment changing parameters $\widetilde{\mathrm{G}}_{0 \mathrm{x}}, \mathrm{K}_{\mathrm{x}}$ almost in any way not influence on GSIF $\widetilde{\mathrm{K}}_{31}, \widetilde{\mathrm{K}}_{32}$ when schema 3 is acting. Unlike of this, changing parameters $K_{y}, G_{d}$ has more perceptible influence on the parameter of difference of matrix materials $G_{d}$ (Fig. 4). Overall, in this case of loading $\widetilde{K}_{31}$ diminishes at appearance of non-linearity, and on $\widetilde{\mathrm{K}}_{32}$ is insignificant.

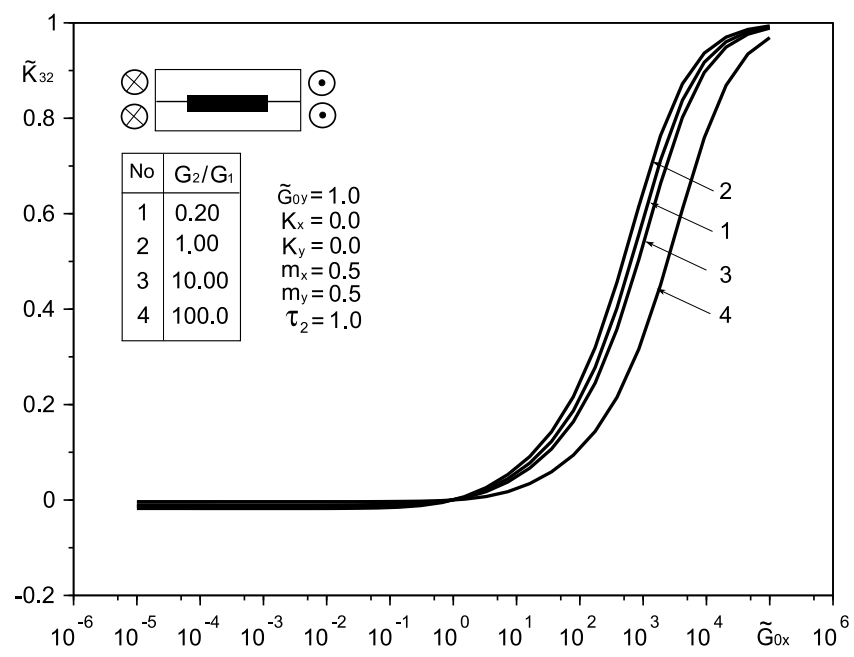

Fig. 3. Dependence of the stress intensity factor $\widetilde{\boldsymbol{K}}_{32}$ on nonlinear elastic parameter $\boldsymbol{G}_{\boldsymbol{d}}$ (scheme 2)
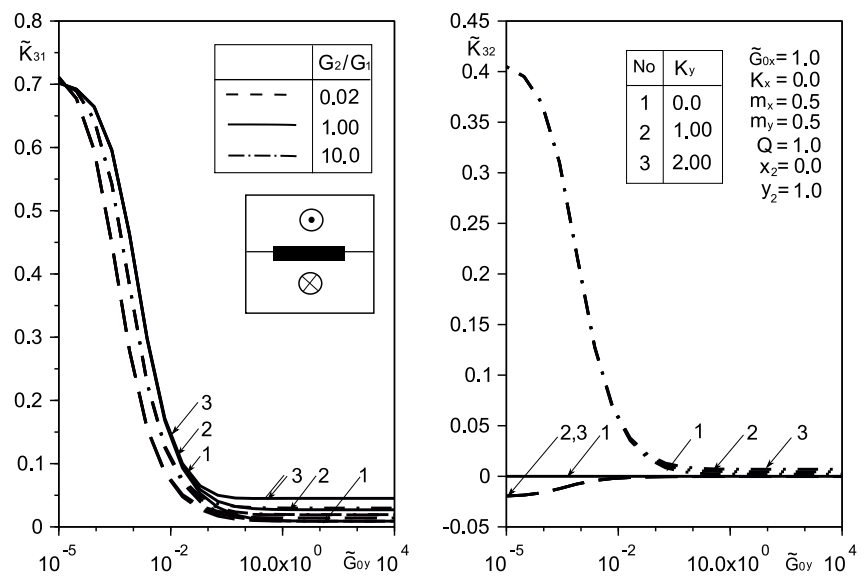

Fig. 4. Dependence of the stress intensity factors $\widetilde{\boldsymbol{K}}_{31}, \widetilde{\boldsymbol{K}}_{32}$ on nonlinear elastic parameters $\boldsymbol{K}_{\boldsymbol{y}}, \boldsymbol{G}_{\boldsymbol{d}}$ (scheme 3)

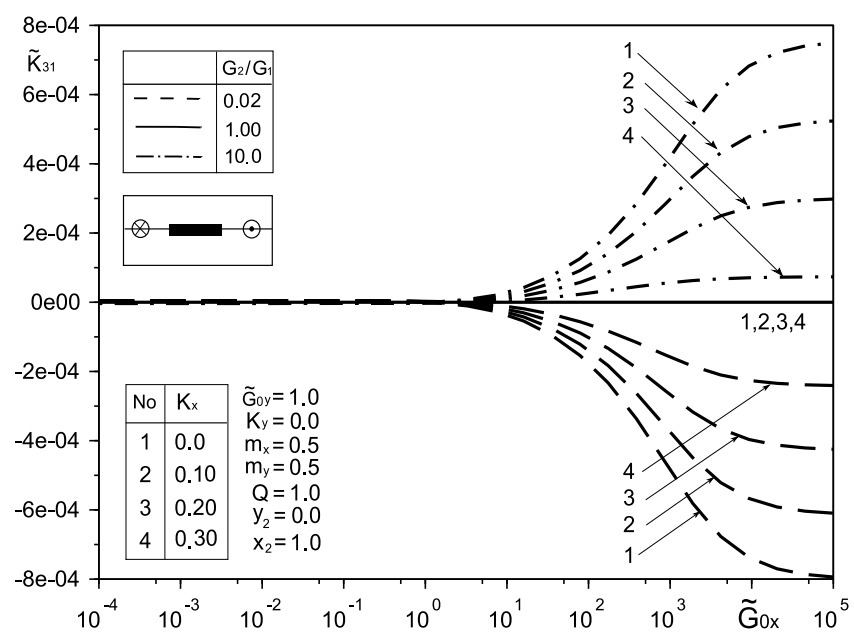

Fig. 5. Dependence of the stress intensity factor $\widetilde{\boldsymbol{K}}_{31}$ on nonlinear elastic parameters $\boldsymbol{K}_{\boldsymbol{x}}, \boldsymbol{G}_{\boldsymbol{d}}$ (scheme 4)

Results of calculations the loading scheme 4 demonstrate, that nonzero values $\widetilde{\mathrm{K}}_{31}$ appear for the "hard" inclusion $\left(\widetilde{\mathrm{G}}_{0 \mathrm{y}}>\right.$ 1 ), grow while $G_{d}$ is increasing and diminish while $K_{x}$ is increasing (Fig. 5). An analogical tendency is observed in this case of loading also for $\widetilde{\mathrm{K}}_{32}$ (Fig. 6). 


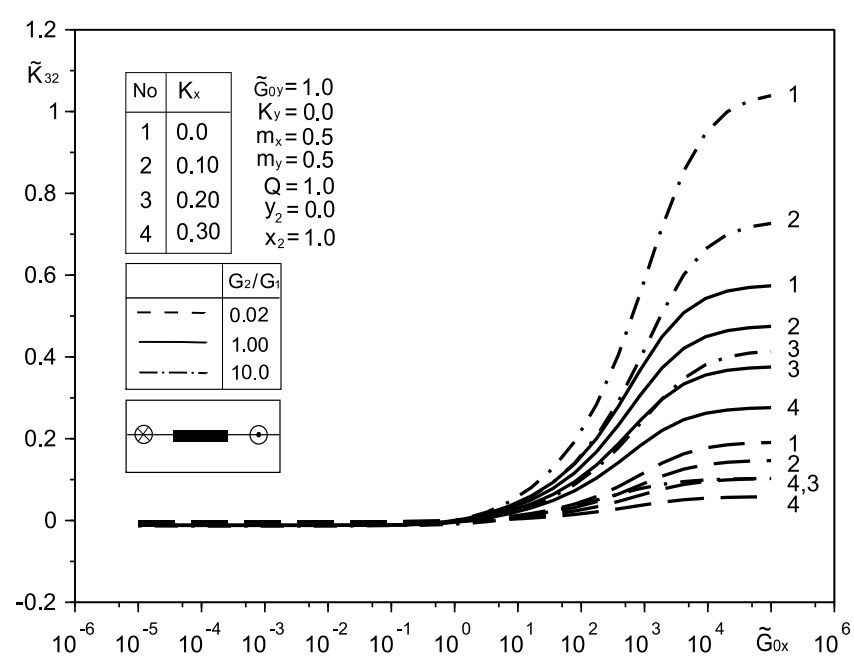

Fig. 6. Dependence of the stress intensity factor $\widetilde{\boldsymbol{K}}_{32}$ on nonlinear elastic parameters $\boldsymbol{K}_{\boldsymbol{x}}, \boldsymbol{G}_{\boldsymbol{d}}$ (scheme 4)
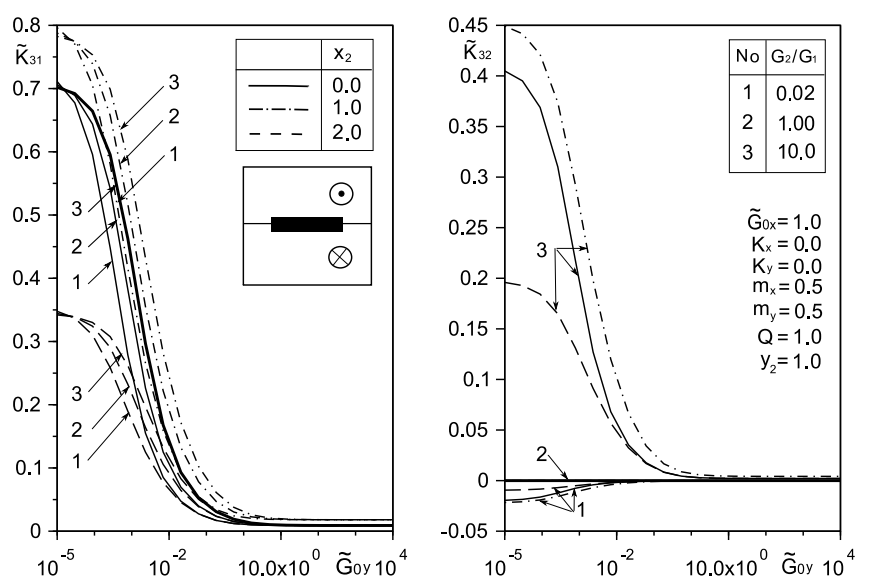

Fig. 7. Dependence of the stress intensity factors $\widetilde{\boldsymbol{K}}_{\mathbf{3 1}}, \widetilde{\boldsymbol{K}}_{\mathbf{3 2}}$ on parameters $\boldsymbol{x}_{\mathbf{2}}, \boldsymbol{G}_{\boldsymbol{d}}$ (scheme 5)
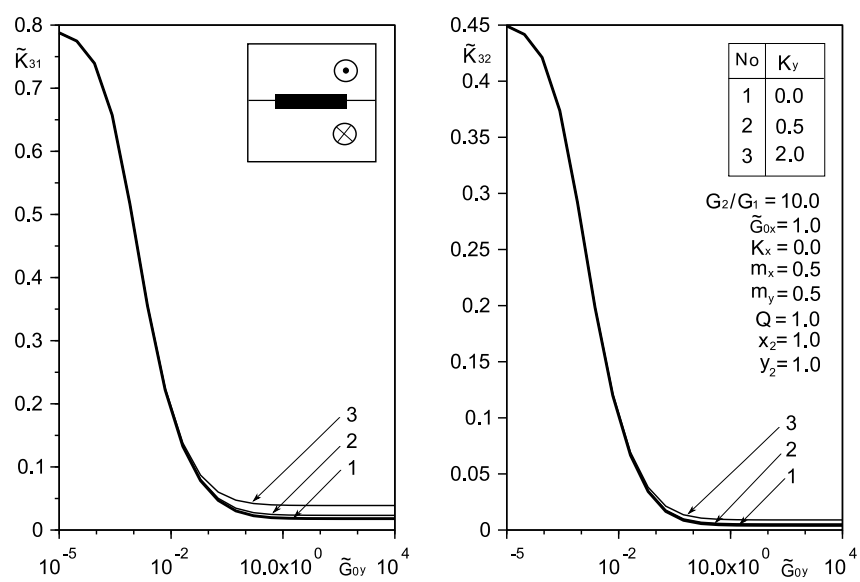

Fig. 8. Dependence of the stress intensity factors $\widetilde{\boldsymbol{K}}_{\mathbf{3 1}}, \widetilde{\boldsymbol{K}}_{\mathbf{3 2}}$ on nonlinear parameter $\boldsymbol{K}_{\boldsymbol{y}}$ (scheme 5)

Fig. 7-9 illustrates the results of calculations for the loading scheme 5. On Fig. 7 the influence of displacement of co-ordinate $\mathrm{x}_{2}$ of the concentrated force application point on GSIF $\widetilde{\mathrm{K}}_{31}, \widetilde{\mathrm{K}}_{32}$ is represented for different values of the parameter of difference of matrix materials $G_{d}$. Notedly, that maximal values GSIF $\widetilde{K}_{31}$ and $\widetilde{K}_{32}$ (only when $G_{d} \neq 1$ ) are reached at $x_{2}=1$, when a point of applying of the concentrated force is exactly above the tip of inclusion.
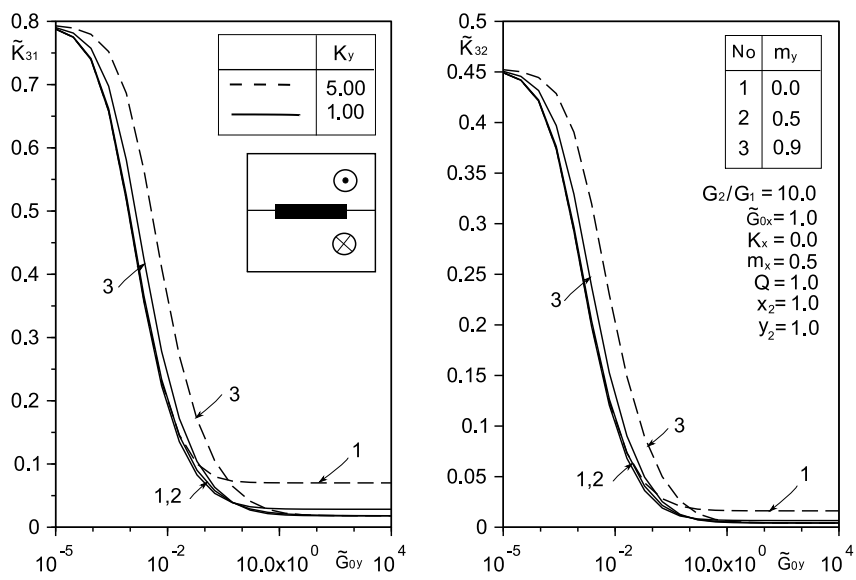

Fig. 9. Dependence of the stress intensity factors $\widetilde{\boldsymbol{K}}_{\mathbf{3 1}}, \widetilde{\boldsymbol{K}}_{\mathbf{3 2}}$ on nonlinear parameter $\boldsymbol{m}_{\boldsymbol{y}}$ (scheme 5)

The influence of parameters of non-linearity $\mathrm{K}_{\mathrm{y}}, \mathrm{m}_{\mathrm{y}}$ on GSIF $\widetilde{\mathrm{K}}_{31}, \widetilde{\mathrm{K}}_{32}$ is showed on Fig. 8,9. It is detected that parameter $\mathrm{K}_{\mathrm{y}}$ brings in greater changes in a result, than $\mathrm{m}_{\mathrm{y}}$.

Thus, for loading where a constituent acts along axis $\mathrm{Oy}$ (schemas $1,3,5$ ), an increase $\mathrm{K}_{\mathrm{y}}$ increases a value GSIF. The increase of parameter $\mathrm{m}_{\mathrm{y}}$ for the "soft" inclusion $\left(\widetilde{\mathrm{G}}_{0 \mathrm{y}}<1\right)$ increases values of GSIF and for "hard" $\left(\widetilde{G}_{0 y}>1\right)$ - diminishes it.

\section{CONCLUSIONS}

The model of thin inclusion with substantially nonlinear mechanical properties is built. Using methods of the coupling problem of boundary values of analytical functions we reduce the problem to SSIE with variable coefficients on jump functions. A consilient iterative numerical-analytical method is proposed to solve such SSIE by reducing it to linear SAE on each step.

Numerical calculations enabled to analyse influence of the parameters of non-linearity in accordance to the Ramberg-Osgood's law of deformation on SSS of body at loading by the balanced system of concentrated forces and by a uniform shear on the infinity.

The result for the considered configurations and tasks revealed the following patterns: 1) the most perceptible influence on the GSIF makes the difference of matrix materials $G_{d}$; 2) the parameter of non-linearity $\mathrm{K}_{\mathrm{s}}$ provides more perceptible effect on GSIF compared with $\left.\mathrm{m}_{\mathrm{s}}, \mathrm{s}=\{\mathrm{x} ; \mathrm{y}\} ; 3\right)$ for loading, where predominant contribution gives a constituent along axis Oy (schemas $1,3,5)$, an increase $\mathrm{K}_{\mathrm{y}}$ increases the value GSIF; 4) the perpendicular direction (along an axis $\mathrm{Ox}$ ) of predominant loading constituent leads to reverse conclusion - increasing of $\mathrm{K}_{\mathrm{x}}$ diminishes value of GSIF; 5 ) the increase of parameter $m_{y}$ for the "soft" inclusion $\left(\widetilde{G}_{0 y}<1\right)$ increases the value of GSIF and for "hard" $\left(\widetilde{G}_{0 y}>1\right)$ - diminishes it; 6$)$ the influence of the parameters of non-linearity is considerably more perceptible for the "soft" inclu- 
sion when $0 y$ - directed predominant loading is acting, unlike the case of the Ox-directed predominant loading acting when "hard" inclusion is more sensitive to the non-linearity.

\section{REFERENCES}

1. Arhipenko K.M., Kriviy O.F. (2008), Interfacial beam at different types of contact interaction of heterogeneous anisotropic plane (in Ukrainian), Mashynoznavstvo, 3(129), 16-21.

2. Bozhydarnyk V.V, Sulym H. (1999), Elements of the theory of plasticity and strength (in Ukrainian), L'viv, Svit.

3. Chernych K.F. (1998), Nonlinear singular elasticity (theory and applications) (in russian, ScPetersburg.

4. Comninou M. (1977), The interface crack, J. Appl. Mech., 44, 631-636.

5. Hills D.A, Nowell D., Sackfield A. (1993), Mechanics of elastic contact, Butterworth-Heinemann, Oxford.

6. Johnson K.L. (1985), Contact mechanics, Cambridge University Press.

7. Kit G.S., Martynyak R.M. and Machishyn I.M. (2003), The effect of fluid in the contact gap on the stress state of conjugate bodies, Ibid, 39(3), 292-299.

8. Ostryk V.I., Ulitko A.F. (2006), Wiener-Hopf method to contact problems of theory of elasticity (in Russian), Kiev, Naukova dumka.

9. Panasyuk V.V., Savruk M.P., Datsyshyn O.P. (1976), Distribution tense neighborhood of cracks in the plates and shells (in Russian), Kiev, Naukova dumka.

10. Pasternak Ya.M., Sulym H.T., Piskozub L.G. (2010), Models of thin inclusion with the account of imperfect contact with the medium (in Russian), Proc. of VI International symposium on Tribo-Fatigue MSTF 2010 (Minsk, 25 oct. - 1 nov. 2010) in 2 parts, part 2., Minsk, BGU, 399-404.

11. Pasternak Ya.M., Sulym H.T., Pasternak R.M. (2012) Longitudinal shear of the body with thin straps and elastic inclusions of variable stiffness at their ideal and nonideal contacts, Mechanika $i$ fizyka ruynuvannia budivelnych konstrukciy, Lviv, Kameniar, 9, 98-113.

12. Piskozub J.Z., Sulim G.T. (2008), Thermoelastic equilibrium of piecewise homogeneous solids with thin inclusions, Journal of Engineering Mathematics. Special Issue Thermomechanics, 61, 315-337.

13. Rice J.R., Rosengren G.F. (1968), Plane strain deformation near a crack tip in power law hardening material, Journal of the Mechanics and Physic of Solids, 16, 1-12.

14. Savruk M.P. (1981), Two-dimensional elasticity problem for bodies with cracks (in Russian), Kiev, Naukova dumka.

15. Schmueser D., Comninou M., Dundurs J. (1980), Separation and slip between a layer and substrate caused by a tensile load, Ibid, 18, $1149-1155$.
16. Sekine H.(1982), Mechanics of debonding along the surfaces of dispersed flat inclusions in composite materials (A model of debonding along the surface of a flat inclusion), Trans. ASME. Journal of Applied Mechanics, 48A, 11(435), 1415-1420.

17. Sulym H., Piskozub L., Piskozub Y., Pasternak la (2015), Antiplane deformation of a bimaterial containing an interfacial crack with the account of friction. I. Single loading, Acta Mechanica et Automatica, 9(2), 115-121.

18. Sulym H., Piskozub L., Piskozub Y., Pasternak la. (2015), Antiplane deformation of a bimaterial containing an interfacial crack with the account of friction. 2. Repeating and Cyclic loading, Acta Mechanica et Automatica, 9(3), 178-184.

19. Sulym H.T., Pasternak Ya.M., Piskozub J.Z., Piskozub L.G. (2015), Longitudinal shear of a bimaterial with frictional sliding contact in the interfacial crack, Journal of Theoretical and Applied Mechanics, 54(2), 529-539.

20. Sulym H.T. (2007), Fundamentals of the mathematical theory of thermoelastic equilibrium of deformable bodies with thin inclusions (in Ukrainian), Lviv, Doslidno-vydavnychyy tsentr NTSh.

21. Sulym H.T., Piskozub Y.Z. (1996), Asymptotics of stresses in the vicinity of thin interface inclusion tips (in Ukrainian), Phis.-chim. mechanica materialiv (Materials Science), 32(4), 39-48.

22. Sulym H.T., Piskozub Y.Z. (2004), Conditions of contact interaction (review) (in ukrainian), Mat. metody i fiz.-meh. polya (Journal of Mathematical Science), 47(3), 110-125. 